\section{A combination of the clip-with-line method and the tunnel technique during esophageal endoscopic submucosal dissection: a technical solution?}

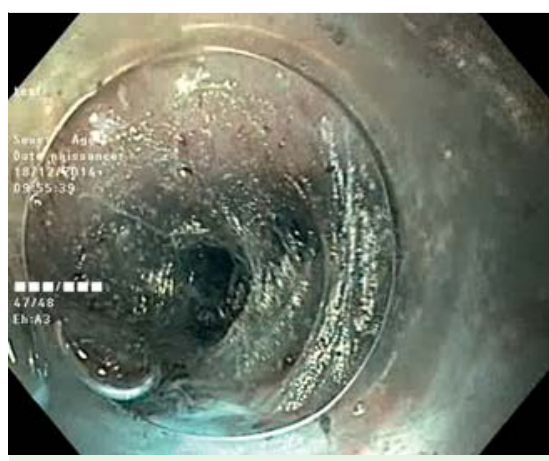

Fig. 1 Submucosal exposure during tunnel dissection of a 3-cm-diameter nodule exhibiting high grade dysplasia and complicating Barrett's esophagus in a 76-year-old woman.

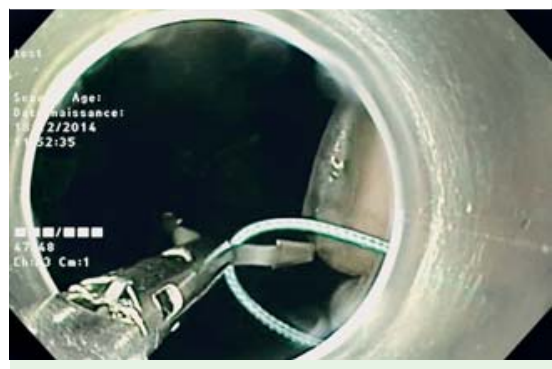

Fig. 2 Clip with attached line.

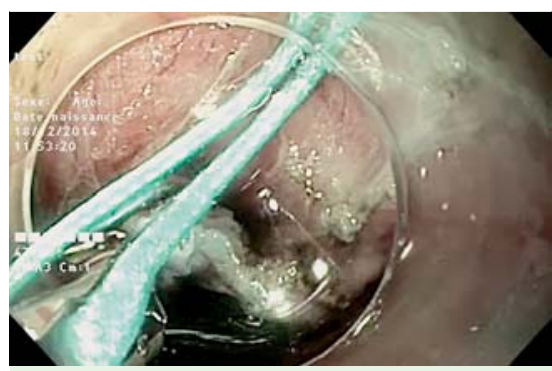

Fig.3 Clipping the proximal side of the tunnel with the attached line.

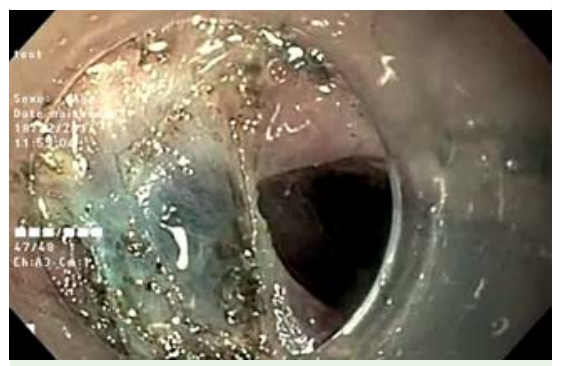

Fig. 4 Countertraction allowing a large exposure of the remaining submucosal layers on the left side.
A 76-year-old woman was referred to our endoscopy unit for endoscopic submucosal dissection (ESD) of a 3-cm-diameter nodule exhibiting high grade dysplasia and complicating a large Barrett's esophagus. A classic tunnel was created beneath the lesion ( $\bullet$ Fig.1) with a HybridKnife Type T (ERBE Electromedizin, Tübingen, Germany). After incision of the mucosa on both sides of the tumor, the scope was withdrawn. A Resolution Clip (Boston Scientific, Natick, Massachusetts, USA) was inserted into the operative channel of the endoscope and attached to a $250-\mathrm{cm}$ line made of nonabsorbable suture wire (Peters Surgical, Paris, France) bent in a U-shape. The scope was reinserted with the line in parallel, and the clip with the attached line was placed at the proximal side of the tunnel ( $\bullet$ Fig. 2 and $\bullet$ Fig. 3 ). Constant countertraction, applied by grasping the external part of the linewith a plastic $11 \mathrm{~g}$ Kocher forceps (Nessicare dressing kit, LCH Medical Products, Paris, France), facilitated excellent exposure of the remaining submucosal layers ( $\bullet$ Fig. 4 and $\bullet$ Fig.5) on both sides, greatly aiding dissection after tunneling ( $\bullet$ Fig. 6 , - Video 1).

The esophagus is often considered the most difficult location in which to perform ESD. The narrow diameter compromises scope maneuverability, and the thin wall increases the risk of perforation [1]. However, esophageal ESD is often essential, as indicated by the epidemiology of early-stage esophageal cancer in Europe and the high morbidity rate associated with esophageal surgical procedures.

Technically, during ESD, it is essential to ensure good exposure of the submucosal layer after circumferential incision. Two relevant methods have been described. First, the clip-with-line method facilitates good countertraction of the lesion [2]. A clip is inserted into the operative channel of the scope, and a line running parallel to the scope is attached to the clip. The scope is reinserted, and the clip is placed at the proximal side of the lesion. Tension (applied with a 10-g weight or gentle, repetitive manual traction) creates coun-

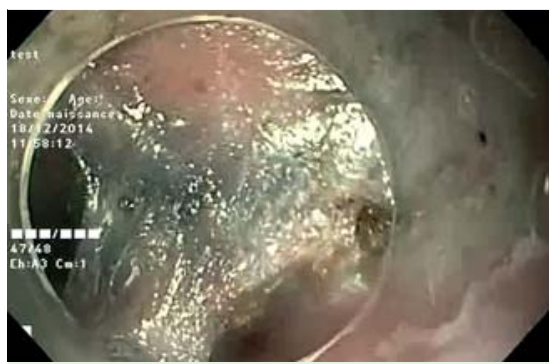

Fig. 5 Countertraction allowing a large exposure of the remaining submucosal layers on the right side.

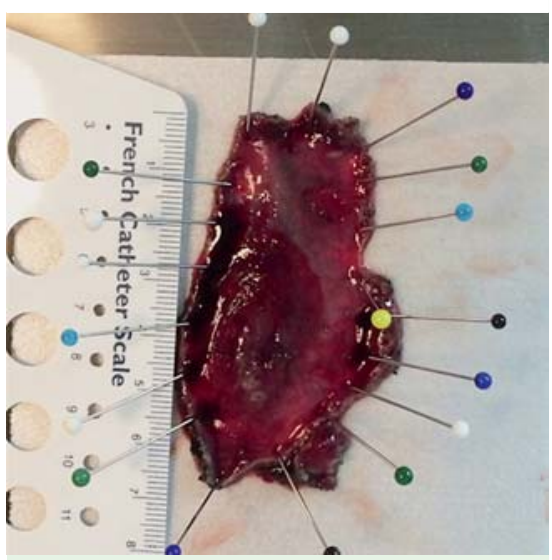

Fig. 6 Specimen at the end of the dissection.

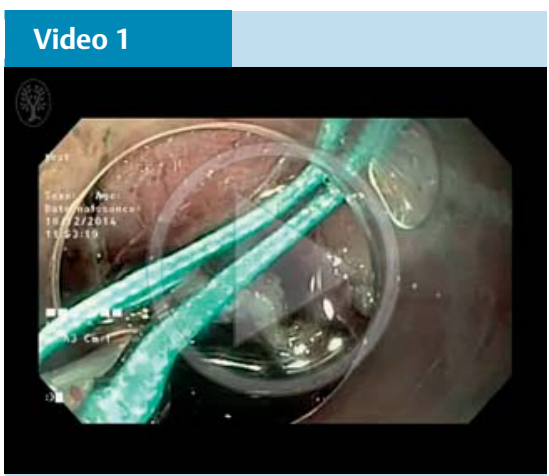

A combination of the clip-with-line method and the tunnel technique during esophageal endoscopic submucosal dissection.

tertraction, which facilitates good exposure of the submucosal layer. However, the clip-with-line method is not a panacea; it is not easy to position the clip effectively, and specimen rotation is still possible, particularly near the end of the procedure.

Other groups have described the tunnel technique [3]. After mucosal incision on the distal side and the proximal side, a submucosal tunnel is progressively created beneath the lesion. This allows good constant exposure of the submucosal 
layer, facilitating quick and safe dissection, especially when a HybridKnife is used. However, the lateral margins of the tunnel are difficult to resect, and at the end of tunneling, resection can be very challenging.

A combination of the clip-with-line method and the tunnel technique greatly facilitates esophageal ESD and may become standard.

Endoscopy_UCTN_Code_TTT_1AO_2AG

Competing interests: None
Jérémie Jacques, Sophie Geyl,

Paul Carrier, Tessa Tabouret,

Veronique Loustaud-Ratti,

Denis Sautereau, Romain Legros

Service d'Hépato-gastro-entérologie,

CHU Dupuytren, Limoges, France

\section{References}

1 Oyama T. Esophageal ESD: technique and prevention of complications. Gastrointest Endosc Clin N Am 2014; 24: 201 - 212

2 Oyama T. Counter traction makes endoscopic submucosal dissection easier. Clin Endosc 2012; 45: 375-378

3 Pioche M, Mais L, Guillaud $O$ et al. Endoscopic submucosal tunnel dissection for large esophageal neoplastic lesions. Endoscopy 2013; 45: $1032-1034$
Bibliography

Dol http://dx.doi.org/

10.1055/s-0034-1392240

Endoscopy 2015; 47: E307-E308

(c) Georg Thieme Verlag KG

Stuttgart · New York

ISSN 0013-726X

Corresponding author

Jérémie Jacques, MD

Service d'Hépato-gastro-entérologie CHU Dupuytren

2 avenue Martin Luther King

87042 Limoges

France

Fax: +33-05-55058733

jeremiejacques@gmail.com 